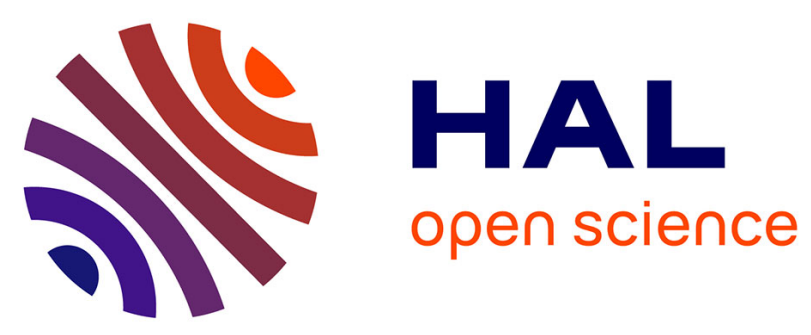

\title{
Hard coatings
}

J. Dan, H. Boving, H. Hintermann

\section{To cite this version:}

J. Dan, H. Boving, H. Hintermann. Hard coatings. Journal de Physique IV Proceedings, 1993, 03 (C7), pp.C7-933-C7-941. 10.1051/jp4:19937144 . jpa-00251766

\section{HAL Id: jpa-00251766 https://hal.science/jpa-00251766}

Submitted on 1 Jan 1993

HAL is a multi-disciplinary open access archive for the deposit and dissemination of scientific research documents, whether they are published or not. The documents may come from teaching and research institutions in France or abroad, or from public or private research centers.
L'archive ouverte pluridisciplinaire HAL, est destinée au dépôt et à la diffusion de documents scientifiques de niveau recherche, publiés ou non, émanant des établissements d'enseignement et de recherche français ou étrangers, des laboratoires publics ou privés. 


\title{
Hard coatings
}

\author{
J.P. DAN, H.J. BOVING and H.E. HINTERMANN
}

CSEM, Maladière 71, Neuchâtel, Switzerland

\begin{abstract}
Hard, wear resistant and low friction coatings are presently produced on a world-wide basis, by different processes such as electrochemical or electroless methods, spray technologies, thermochemical, CVD and PVD. Some of the most advanced processes, especially those dedicated to thin film depositions, basically belong to CVD or PVD technologies, and will be looked at in more detail. The hard coatings mainly consist of oxides, nitrides, carbides, borides or carbon.

Over the years, many processes have been developed which are variations and/or combinations of the basic CVD and PVD methods. The main difference between these two families of deposition techniques is that the CVD is an elevated temperature process $\left(\geq 700^{\circ} \mathrm{C}\right)$, while the PVD on the contrary, is rather a low temperature process $\left(\leq 500^{\circ} \mathrm{C}\right)$; this of course influences the choice of substrates and properties of the coating/substrate systems.

Fundamental aspects of the vapor phase deposition techniques and some of their influences on coating properties will be discussed, as well as the very important interactions between deposit and substrate: diffusions, internal stress, etc.. Advantages and limitations of CVD and PVD respectively will briefly be reviewed and examples of applications of the layers will be given.

Parallel to the development and permanent updating of surface modification technologies, an effort was made to create novel characterisation methods. A close look will be given to the coating adherence control by means of the scratch test, at the coating hardness measurement by means of nanoindentation, at the coating wear resistance by means of a pin-on-disc tribometer, and at the surface quality evaluation by Atomic Force Microscopy (AFM).
\end{abstract}

Finally, main important trends will be highlighted.

\section{INTRODUCTION}

It has always been a wish of mechanical engineers to extend the lifetime of tools, mechanical components or wear parts, by increasing the "surface hardness". Over the last 50 years, many processes have been developed to increase the surface hardness by diffusion and/or coating deposition techniques; each of these techniques were designed to be applied on specific materials and/or specific applications. The following surface modification techniques can briefly be mentioned:

\section{Electrochemical and Chemical Methods}

Hard Chromium Plating produced by electrodeposition, is extremeiy hard and corrosion resistant. The coating is used for rebuilding defective or worn parts, for automotive valve stems, piston rings, bores of diesel and aircraft cylinders, and for hydraulic shafts. Hard chromium plating is deposited in thicknesses ranging from 2.5 to $500 \mu \mathrm{m}$; the Vickers hardness is between 900 and 
1100. Most hard chromium deposits are applied to parts made of ferrous alloys, however, numerous aerospace applications require the chromium plating of $\mathrm{Al}$, $\mathrm{Ti}$ or $\mathrm{Ni}$ base alloys. More information concerning hard plating can be found in the literature (1).

Electroless or Chemical Nickel Plating is used to deposit Ni without the use of an electric current. Electroless $\mathrm{Ni}$ is an engineering coating, normally used because of excellent corrosion and wear resistance. Composites are one of the most recently developed types of electroless coatings. These cement deposits consist of small particles of intermetallic compounds, carbides, or diamonds, dispersed in an electroless Ni-P matrix. The resulting apparent surface hardness is $1300 \mathrm{HV}$ or more. This hard surfacing technique is extensively covered in the literature (2).

\section{Spray Coatings}

Thermal Spray is the generic term of a group of commonly used processes for depositing metallic and nonmetallic coatings. These processes, sometimes known as metallizing, are flame spray, highvelocity oxyfuel, plasma-arc spray and electric-arc spray. Coatings can be sprayed from rod, wire stock or from powdered material. The hard coatings are mostly based on hard materials such as oxides, carbides or nitrides; particles distributed in a metallic matrix. The adhesion of these types of coatings is mainly mechanical; often, the substrates are previously sandblasted to increase the roughness in order to enhance the mechanical adherence. Typical coating thicknesses are 50-300 $\mu \mathrm{m}$. Such coatings are commonly used on complicated/expensive mechanical parts (bearings) where important wear has taken place and where a replacement of the complete part is not economical. In order to cover large surfaces, the workpiece is in movement with respect to the spray gun. In order to increase the deposition thickness, it is possible to pass several times over the surfaces to be coated. For mechanical parts with narrow tolerances, the coatings cannot be used as such; there is need for precision grinding and/or polishing before use. There is presently an important series of specific technologies belonging to the category of Spray Coatings, but only basic principles are mentioned here (3):

Flame Spray: Solid material , aspirated into the oxygen/fuel-gas flame, is melted and carried by the flame onto the workpiece $\left(\sim 2800^{\circ} \mathrm{C}\right)$. The particle velocity is relatively low, and the bond strength of deposits is low. The porosity is high and the cohesive strength is low. Spray rates are usually in the range of 0.5 to $9 \mathrm{~kg} / \mathrm{h}$ and the approximate particle impact velocity is $30 \mathrm{~m} / \mathrm{s}$.

- Plasma Spray: Conventional plasma spraying provides free-plasma temperatures in the melting region in the order of 4000 to $5000^{\circ} \mathrm{C}$. To generate the plasma, on inert gas is superheated by passing it through a DC arc. Solid material is introduced and carried to the workpiece by the plasma stream. The substrate temperature can be kept at 100 to $200^{\circ} \mathrm{C}$. Typical spray rates are $0.1 \mathrm{~kg} / \mathrm{h}$, and the approximate particle impact velocity is $250 \mathrm{~m} / \mathrm{s}$.

- D-gun (Detonation gun): Suspended powder is fed into a $1 \mathrm{~m}$ long tube (barrel) along with the oxygen and fuel gas. A spark ignites the mixture and produces a controlled explosion. The high temperatures $\left(\sim 3900^{\circ} \mathrm{C}\right)$ and pressures $(1 \mathrm{MPa})$ that are generated blast the particles out of the end of the tube towards the substrate. The approximate particle impact velocity is $900 \mathrm{~m} / \mathrm{s}$.

- Plasma Torch Flame: More recently, a new type of plasma spray has been developed. It is also based on a gas-jet, but the plasma is created by a RF induction coil; temperatures in the order of $8000^{\circ} \mathrm{K}$ can be reached. Such a torch can be used to produce hard coatings on selected substrates. The material to be deposited is introduced as solid powder, or as vapor of chemical compounds. In the latter case the coating is formed by chemical vapor processes in the torch itself and on the substrate surface (4). It can be considered as a high purity chemical reactor and be used for different kinds of deposition (8). 


\section{Thermochemical Coatings}

Totally different processes were developed to thermochemically harden more particularly the surface of steels. These surface hardening techniques are based on diffusion methods which modify the chemical composition of the surface with hardening species such as carbon, nitrogen or boron. Diffusion methods allow effective hardening of the entire surface of a part, and are generally used when a large number of parts are to be surface hardened. The carburizing and nitriding processes are briefly described hereafter.

- Carburizing:

In carburizing, a high-carbon surface layer is imparted to low-carbon steel by heating it in contact with carbonaceous materials. On quenching after carburising, the high-carbon "case" becomes very hard (martensite), while the low-carbon core remains comparatively soft. While the basic principle of carburizing has remained unchanged, the method used to introduce the carbon into the steel has been a matter of continuous evolution; the following techniques exist:

- Gas carburizing

- Vacuum carburizing

- Plasma carburizing

- Salt Bath carburizing

- Pack carburizing

Typical thicknesses of the hardened zones are 50 to $200 \mu \mathrm{m}$ and hardnesses of $700 \mathrm{HV}$ can be reacted. More details can be found in the literature $(5,6)$.

- Nitriding:

The nitrogen case-hardening process which is termed "nitriding" consists in subjecting machined and preferably heat treated parts to the action of a nitrogenous medium, under certain conditions whereby surface hardness is imparted to the material without any further treatment. For increased performance, the nitriding can be performed at reduced gas pressure under plasma = ion-nitriding. The surface hardening effect is due to the diffusion of nitrogen into the steel (containing strong nitride-forming elements such as $\mathrm{Al}, \mathrm{Cr}, \mathrm{V}$ and $\mathrm{Mo}$ ) and to the subsequent formation of dispersed nitrides (6).

- Combined Techniques:

Surface hardening with carbon and nitrogen, offers processing temperatures between those of carburizing and nitriding. In general, there are 3 techniques that use carbon and nitrogen for surface hardening:

- Carbonitriding

- Austenitic nitrocarburising

- Ferritic nitrocaburizing

The interested reader shall refer to the literature for detailed indications on these hard surfacing technologies (7).

\section{CVD and PVD Techniques}

CVD (Chemical Vapour Deposition) was practised on a laboratory scale since early in the century. The first industrial application of this process to produce hard, wear resistant coatings, took place in the late sixties, when thousands of cemented carbide cutting inserts were coated with thin (typically $3 \mu \mathrm{m}$ ) layers of carbides (mainly in Ti), and oxides (mainly of Al). PVD (Physical Vapor Deposition) was also known many years before the breakthrough to produce hard, wear resistant coatings (consisting mainly of TiN) took place in the late seventies. Today, these two surface modification techniques are widely used in many different industrial fields. Besides, there have lately been serious efforts to improve the processes, to develop more performing CVD or PVD and to combine the two into complex advanced surface modification techniques. 


\subsection{CVD Techniques}

These techniques are achieved by a chemical gas-phase reaction occurring on a heated substrate, depending on controlled temperature, pressure and flow. Chemical and physical phenomena involved in CVD are complex and there are strong relations between chemical reactions and transport processes such as diffusion and convection.

Fundamental process steps are:

- Gas phase reaction leading to activated species.

- Transport of the reactant to the surface.

- Absorption of the reactant on the surface

- Chemical reaction on the surface

- Eventual diffusion of the atoms in the substrate.

- Desorption of product gases

- Transport of by products

This complexity is increased by the number of reactants or by the enhancement of the reaction using either a special surface preparation, Plasma or Photo-assisted CVD (laser or UV).

A trend towards mixing deposition technologies and including CVD in other methods can be noted:

Flame technology derived directly from flame spray, creating Diamond films, especially experimental growth of large single crystals.

High Frequency Induced Plasma Torch as described in point 2, can also be considered as a CVD reactor.

\section{Advantages and Limitations of CVD are mainly :}

\section{Advantages:}

- Deposition of refractory materials at temperatures far below their melting points,

- Near-theoretical or controlled density of deposit,

- Preferred grain orientation of deposit possible,

- Controlled grain size of deposit,

- Epitaxial grain growth possible including doping capabilities,

- Best method for depositing in holes and recessed areas and create selective deposited areas,

- Processing at atmospheric pressure as well as reduced or high pressure possible,

- Generally good bonding.

\section{Limitations:}

- Need for elevated temperature $\left(>700^{\circ} \mathrm{C}\right)$, which limits the choice of substrates,

- High cost of some reactants,

- Corrosive, toxic or moisture sensitive characteristics of most reactants necessitating a closed system,

- Low Yield of the reaction,

- Because of the wide range of properties of the reactants used, a single piece of equipment can only be used for a limited variety of coatings and substrate shapes.

When one limitation is of critical importance, PVD techniques are very often considered. In this case, physical processes play a dominant role even if reactive gases are added during the process (i.e. reactive sputtering). 


\subsection{PVD Techniques}

The most known PVD techniques are shortly described here below :

\section{Vacuum evaporation}

Heating of the compounds in high vacuum produces vapour which condenses on the substrates. This simple and widely used method produces depositions of relatively low adhesion characteristics due to the poor bonding between the layer and the substrate.

\section{Sputtering}

Argon is admitted in the vacuum chamber at a pressure about $1 \mathrm{~Pa}$, and a DC or RF high voltage is applied to the target, thus creating a gas discharge between the target and the substrate holder. Argon ions, created during the discharge, strike the target with high energy and liberate atoms from the target. These atoms will be deposited onto the substrate to a thin coating.

\section{Ion plating}

A conventional evaporation source (i.e electron beam gun) produces the vapour of the compound. A plasma discharge is then generated between the source and the substrate, using an inert gas at low pressure. The ions impinge the surface during deposition causing changes in the interface region and improving the film properties. This effect is enhanced by biasing the substrate negatively.

\section{Ion implantation}

It is a surface modification process in which ions with high energy ( $1 \mathrm{KeV}-1 \mathrm{MeV})$ are driven into a substrate at room temperature. Ions of almost any atom species can be implanted, but Nitrogen is widely used to improve the tribological properties of steels and other alloys. Since the implantation takes place at room temperature, there is a minimum diffusion-controlled formation of precipitates and deformation of the substrate microstructure. Ion implantation is a complex, nonequilibrium process that creates significant lattice damage in the form of vacancies and interstitial point defects. Concentrations of implanted species much higher than equilibrium solubility limits may be introduced. This method is used in very special cases: razor blades, knifes, a variety of steel tool applications, 52100 and AISI $440 \mathrm{C}$ bearing parts. Post thermal annealing is often required in order to stabilize the substrate.

\section{Advantages and Limitations of PVD are mainly :}

\section{Advantages:}

- Deposition of refractory materials below their melting point

- Low temperature of the substrates

- Complex thin film structure achievable

- Cleanliness and low quantity of by-products

\section{Limitations:}

- Cost

- Generally inferior adherence of layers

- Doping uneasy to achieve

- Flexibility

\section{Applications}

Some applications of hard coatings based on Titanium are summarized in table I. Hardness data indicated were obtained during laboratory work and confronted to typical data compiled in literature. 
TABLE I

\begin{tabular}{|l|c|c|c|l|}
\hline & Materials & Typical Method & Typical Hardness & Applications \\
\hline Nitrides & $\mathrm{TiN}$ & PVD & $2^{\prime} 100-3^{\prime} 500$ & $\begin{array}{l}\text { Cutting Tools } \\
\text { Inserts } \\
\text { Corrosion Barrier }\end{array}$ \\
\hline Carbides & $\mathrm{TiC}$ & $\begin{array}{l}\text { CVD } \\
\text { PVD }\end{array}$ & $2^{\prime} 800$ & $\begin{array}{l}\text { Inserts } \\
\text { Ball Bearings, } \\
\text { Gears, Shafts }\end{array}$ \\
\hline Carbonitrides & $\mathrm{TiCN}$ & $\begin{array}{l}\text { CVD } \\
\text { PVD }\end{array}$ & $3^{\prime} 100-3^{\prime} 900$ & Culting Tools \\
\hline Oxides & $\mathrm{TiO}_{2}$ & $\begin{array}{c}\text { Plasma CVD } \\
1^{\prime} 100\end{array}$ & $\begin{array}{l}\text { Piezoresistivity } \\
\text { Packaging } \\
\text { Mechanical } \\
\text { Reinforcement of } \\
\text { Optical Fiber } \\
\text { Diffusion Barrier }\end{array}$ \\
\hline Borides & $\mathrm{TiB}_{2}$ & CVD & $3^{\prime} 000-3^{\prime} 700$ & $\begin{array}{l}\text { Cutting Tools } \\
\text { Electrical Contact/ } \\
\text { Electrodes } \\
\text { Corrosion Barrier }\end{array}$ \\
\hline
\end{tabular}

Diamond as a specific material, and due to research done on this subject in the past years, has a very large field of applications; but there are also limitations (i.e. tools for iron machining). In any case, this material has very strong potential capabilities, as summarized in table II.

TABLE II

\begin{tabular}{|c|c|c|c|c|}
\hline $\begin{array}{l}\text { Application } \\
\text { Field }\end{array}$ & Material & Method & Key Properties & Applications \\
\hline Mechanical & $\begin{array}{l}\text { Diamond } \\
\text { DLC }\end{array}$ & $\begin{array}{c}\text { Flame } \\
\mu W-C V D \\
\text { TF-CVD } \\
\\
\text { RF-Sputtering }\end{array}$ & $\begin{array}{l}\text { Adhesion } \\
\text { Hardness } \\
\text { Rigidity } \\
\text { Corrosion } \\
\text { Resistance } \\
\text { Tribological Behaviour }\end{array}$ & $\begin{array}{l}\text { Tool Blade Coating } \\
\text { TAB Tool } \\
\text { Cutting Inserts }\end{array}$ \\
\hline Electronics & Diamond & $\begin{array}{l}\text { TF-CVD } \\
\mu \mathrm{W}-\mathrm{CVD}\end{array}$ & $\begin{array}{l}\text { Heat Conductivity } \\
\text { Corrosion Resistance } \\
\text { Electrical properties } \\
\text { (Dielectric Constant) } \\
\text { and Resistivity }\end{array}$ & $\begin{array}{l}\text { Sensors } \\
\quad \text { Heat Sink }\end{array}$ \\
\hline Optical & Diamond & $\begin{array}{r}\text { TF-CVD } \\
\mu \mathrm{W}-\mathrm{CVD}\end{array}$ & $\begin{array}{l}\text { Rigidity } \\
\text { Optical Transmission } \\
\text { Wear Resistance }\end{array}$ & $\begin{array}{l}\text { IR Windows } \\
\text { XR Windows }\end{array}$ \\
\hline $\begin{array}{l}\text { Micro- } \\
\text { technique }\end{array}$ & Diamond & $\begin{array}{l}\text { TF-CVD } \\
\mu \mathrm{W}-\mathrm{CVD}\end{array}$ & $\begin{array}{l}\text { Rigidity } \\
\text { Electrical and } \\
\text { Piezoelectrical } \\
\text { Properties }\end{array}$ & Diaphragm \\
\hline Packaging & $\begin{array}{r}\text { Diamond } \\
\text { DLC }\end{array}$ & $\begin{array}{c}\text { TF-CVD } \\
\mu W \text {-CVD } \\
\text { Rf-Sputtering }\end{array}$ & $\begin{array}{l}\text { Corrosion resistance } \\
\text { Passivation } \\
\text { Heat Transfer }\end{array}$ & $\begin{array}{l}\text { Tools for Bonding } \\
\text { Optical Fiber }\end{array}$ \\
\hline
\end{tabular}




\section{Coating Characterisations}

There are in reality many methods to characterise surfaces, coatings or interfaces. Each of these techniques are adapted to a set of conditions related to coating hardness, thickness, substrate nature, etc. Until approximately 10 years ago, there were practically no characterisation methods for the evaluation of thin films with typical thickness of 1 to $10 \mu \mathrm{m}$. Even now most of these methods are relative. It is not the purpose of the authors to make an exhaustive review of the characterisation methods; instead, attention will be given to adhesion, hardness, wear resistance and surface quality characterisation of thin CVD and PVD types of coatings.

\subsection{Coating adhesion}

Coating adhesion is mostly measured using the tape method, pull-off test, shock wave loading method and scratchtest. Among these methods, scratch testing has proved to be very reliable. The basic principle is well known (9), but recent advance, mainly in the loading charge and sensitivity of the sensor, has given significant results in the measure of thin films coatings (10), and even measurement of the adhesion of thin organic films can be achieved, in a reliable manner.

\subsection{Hardness measurement of coatings}

Hardness, and today microhardness testing is a key point for characterization of the quality of coatings. With a background of experiments of nearly 10 years (11-12), micro-identation testing techniques can provide important information about near surface mechanical and deformation properties of solids.

Difficulties of the microhardness testing methods are connected to the interpretation of curves which are obtained; discrimination between temperature effect (mostly eliminated in new equipment) plastic, elastic deformation, and crack generations, is often very difficult. Coupling with AFM allows in some cases an easier curve interpretation and combined instruments are showing good possibilities.

\subsection{Coating wear resistance}

There too, many techniques can be used. Among them, pin-on-disk systems are rather extensively used in the industry and comparative data is obtainable.

In this instrument the pin or the ball is pressed onto the rotating disk by the weight of a fixed known load. The friction coefficient is determined during the test by measuring the deflection of the elastic arm, which is positioning the pin at an almost fixed point. Using a surface profilometer, the disk wear is measured at the end of the test. This test can be performed with lubricants or liquids and/or made under controlled atmosphere. Recent development allows measurement under vacuum (13) or at temperatures up to $800^{\circ} \mathrm{C}$ for a short period of time (14).

\subsection{Coating surface quality}

Recent advances in Scanning Force Microscopy (SFM or AFM) have shown excellent results in micro-roughness characterization as well as in nanotribological applications. The method consists in scanning a cantilever-stylus over a sample. By recording the deflection of the cantilever beam as a function of its position, three dimensional images of the sample surface with up to atomic scale resolution can be obtained. Comparative results between $\mathrm{TiC}$, stainless steel and silicon nitride are shown here below. 


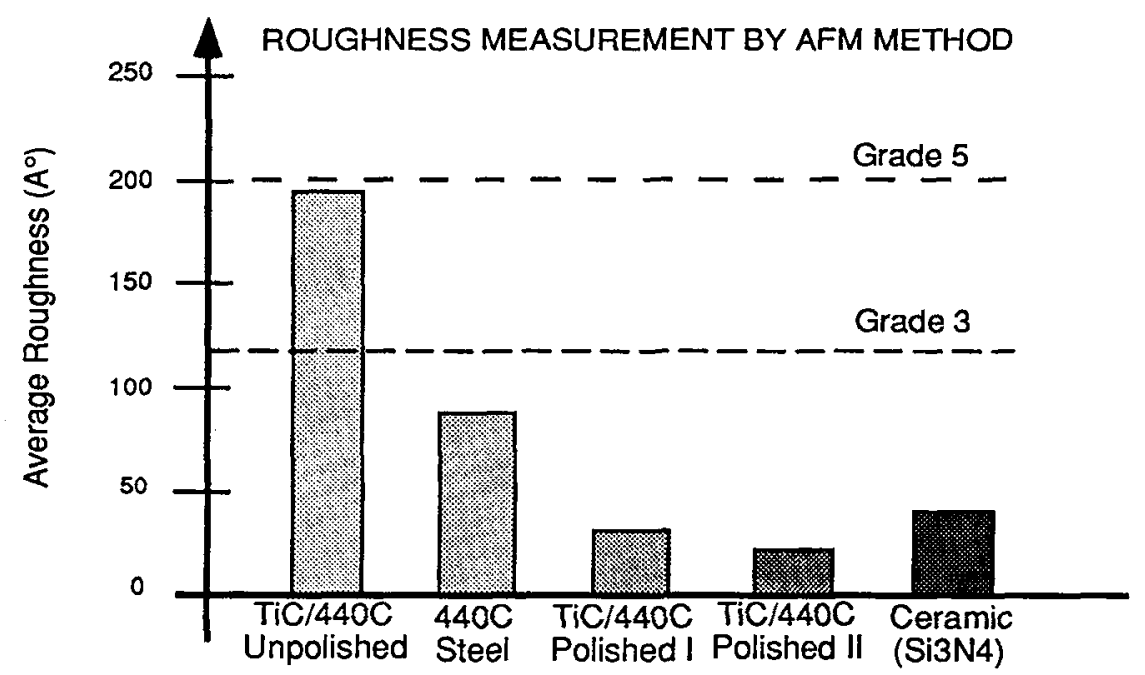

Another interesting field is now opening with the use of this principle to measure friction coefficient at the scale of some nanometers.

\section{Conclusion}

There is presently a shift towards more sophisticated surface engineering (15), where the combination of two or more specific properties are needed. This will induce a more extensive knowledge and comprehension of the process of ${ }^{3}$ physics and chemistry. Tight connections between experts of different fields, and the use of extended methods of characterization will be key factors for the success. On the other hand, temperature and size (i.e. nanometric scale layers or clusters) reduction will need combination of processes or technologies.

Furthermore, the cost reduction or the benefits brought by improved processes will be the key issue for the acceptance by the industry.

Last but not least, environmental requirements will drive to dry processing and processes which can take care of hazardous by-product disposals.

\section{References}

[1] R. Weiner, A: Walmsley, Chromium Plating, England: Finishing Publications Ltd., 1980

[2] W. B. Martin, et al, Electroless Ni Composites, The Second Generation of Chemical Plating, Electroless Nickel Conference, Cincinnati, Nov. 1979.

[3] M. L. Thorpe, Thermal Spray, Advanced Materials and Processes, 5, 1993 (50-61)

[4] H. Berthou, V. Neuman, H. E. Hintermann, High-Frequency inductively coupled torch (HFICP) for pure and doped Silica Deposition, International Conference on Metallurgical Coatings and Thin Films, San Diego, CA, 1993

[5] C. A. Stickels, C. M. Mack, Overview of Carburizing Processing and Performance, G. Krauss, Ed., ASM International, 1989, p. 1-9.

[6] W. L. Kovacs, Ionnitriding and Ion Carburizing, ASM International, 1990, p.5-12.

[7] J. Slycke, T. Ericsson, A Study of Reaction occuring during the Carbonitriding process, J. Heat Treat., Vol 2, $\mathrm{N}^{\circ} 1,1981$, p. 3-19

[8] A. Feldman, L.H Schwartz, U.S Assessment of the new Diamond Technology in Japan, Diane publishing Co.,1991 
[9] P.R Chalker, S.J Bull, D.S Rickerby, A review of the methods for the evaluation of coatingsubstrate adhesion, Materials Science and Engineering, A140, 1991, p 583-592

[10] C. Julia-Schmutz, H.E. Hintermann, Microscratch-testing to characterise the adhesion of Thin Layers, Surface and Coating Technology, 48, 1991, 1

[11] J. Pethica, R. Hutchings, W.C. Oliver, Philos. Mag, A48, 593, 1993

[12] J.L Loubet, J.M Georges, J.M Marchesini, G. Meille, J. of Tribology 106,43, 1983

[13] M. Maillat, H. Kocher, Development of a Vacuum Tribometer, CSEM scientific report, 1991

[14] M. Maillat, Tribometre à haute température et à charge variable, CSEM rapport scientifique, 1990

[15] T. Bell, Towards designer surfaces, Metals and Materials, August 1991, p 478-485 